\title{
Historical perspectives of The American Association for Thoracic Surgery: David C. Sabiston, Jr (1924-2009)
}

\author{
Thomas A. D'Amico, MD, and The American Association for Thoracic Surgery Centennial Committee
}

David Coston Sabiston, Jr, one of the most accomplished, influential, and respected leaders in modern surgery, was born on his grandfather's farm in Onslow County, in eastern North Carolina, on October 4, 1924, to Frances Marie Sabiston and David C. Sabiston, Sr. ${ }^{1}$ He received his undergraduate degree from the University of North Carolina (Phi Beta Kappa) in 1943 and his medical degree from the Johns Hopkins University School of Medicine (Alpha Omega Alpha) in $1947 .^{2}$ As a medical student, he first encountered Dr Alfred Blalock, who would become a greatly respected mentor. Dr Blalock would frequently call Sabiston to run the film projector for visiting dignitaries who came to Hopkins to learn more about the Blalock procedure for tetralogy of Fallot. When he was a thirdyear medical student, Sabiston went to Dr Blalock to inquire about doing research in the Hunterian Laboratory, and he was assigned to work with Drs William Longmire and Mark Ravitch on the pathophysiology of traumatic shock, igniting his desire for a career in academic surgery. ${ }^{1}$

Dr Sabiston entered the residency in general and thoracic surgery at Hopkins in 1947, and he was awarded the Cushing Fellowship to continue research with Drs Rollins Hanlon and H. William Scott. On completing the residency, Dr Sabiston met with Dr Blalock, who informed him "You know, you are going to stay on the faculty." ${ }^{1}$ This came as an overwhelmingly happy surprise. Dr Blalock then told him: "I have a specific plan for you; I want you to develop coronary artery surgery at Hopkins." This also came as a surprise, but not a pleasant one, because the field of coronary surgery did not yet exist, and Dr Sabiston was interested in congenital heart surgery.

After completing the residency, Dr Sabiston served for 2 years in the US Army Medical Corps, and, to improve his understanding of the coronary circulation, he sought a position in the Department of Cardiovascular Research at the Walter Reed Medical Center, where he studied the physiology and pathophysiology of the coronary arteries under Dr Donald Gregg. This experience was pivotal to his

\footnotetext{
From the Department of Surgery, Duke University Medical Center, Durham, NC. Disclosures: Authors have nothing to disclose with regard to commercial support. Received for publication July 2, 2014; accepted for publication July 6, 2014; available ahead of print Aug 16, 2014.

Address for reprints: Thomas A. D'Amico, MD, Department of Surgery, Duke University Medical Center, Box 3496, Duke South, White Zone, Rm 3589, Durham, NC 27710 (E-mail: damic001@mc.duke.edu).

J Thorac Cardiovasc Surg 2015;150:275-8

$0022-5223 / \$ 36.00$

Copyright (C) 2015 by The American Association for Thoracic Surgery http://dx.doi.org/10.1016/j.jtcvs.2014.07.010
}

eventual success in forwarding the surgical approach to coronary artery disease.

In 1952, during his year as a chief resident, Dr Sabiston served as an Instructor in Surgery. He joined the faculty at Hopkins as Assistant Professor of Surgery in 1953 and an investigator at the Howard Hughes Medical Institute. ${ }^{2}$ During the next 8 years, he proved himself to be a productive and respected member of the faculty. In 1961, he received a Fulbright Research Scholarship to study at 2 prestigious British institutions: the Hospital for Sick Children (Great Ormond Street) of the University of London, where he studied with Sir William Dunn and Nobel Prize winner Howard W. Florey (studying coronary atherosclerosis), and the Nuffield Department of Surgery at Oxford University under $\mathrm{Mr}$ Phillip Allison (studying pulmonary thromboembolism).

On his return to Baltimore, he devoted much time and energy to developing a strategy for the surgical treatment of coronary artery disease, an effort that was influenced by his extensive experience in coronary physiology with Dr Gregg and his experience at Oxford. He began to perform coronary endarterectomy for patients with angina but found that the benefit of this procedure lasted only 1 year. $^{3}$ On April 5, 1962, he performed the first recorded coronary artery bypass, grafting the saphenous vein from the aorta endto-end to the right coronary artery. Because the patient died (of unrelated complications), Dr Sabiston was discouraged from immediately pursuing additional procedures until others had reported on it 2 years later, a decision he later regretted. Nevertheless, this landmark procedure demonstrated the feasibility of coronary artery bypass and was a cornerstone of the development of the field of coronary revascularization. ${ }^{4}$

Within 10 years of joining the faculty at Johns Hopkins, he was promoted to Professor of Surgery. Dr Sabiston considered a number of chair positions during his tenure at Johns Hopkins; however, his mentor, Dr Blalock, counseled him to find the institution where he would have the best effect. ${ }^{5}$ After 11 years on the faculty at Johns Hopkins, Dr Sabiston was successfully recruited to Duke University in 1964 to replace Dr Deryl Hart as the Chairman of the Department of Surgery. Dr Sabiston became the James B. Duke Professor and Chair of the Department of Surgery, a position he would hold for 30 years. Early in his tenure in Durham, Dr Sabiston helped to desegregate the surgical clinics and wards at Duke University Hospital. ${ }^{2} \mathrm{He}$ also worked toward the elimination of the pyramidal system of training in surgery, adopting a rectangular system soon after coming to Duke. Finally, shortly after becoming Chair of 
Surgery at Duke, Dr Sabiston dedicated the department to provide the means for every surgery resident to spend 2 years in basic research during clinical training. His philosophy was that the best surgeons were curious and competent scientists, as well as technically proficient surgeons. ${ }^{4}$

In 1965, Dr Sabiston married Ms Agnes Barden, and they went on to raise 3 daughters, Agnes, Ann, and Sarah. His family was important to him and well known to the residents and faculty in the Department of Surgery. During the winter holidays, he would host the Department (and others) in his home on 2 consecutive nights, so that every single member of the Department could attend in an era of every-other-night call. In addition, every intern who came to Duke attended a dinner in his home before the first day on service. One of the most memorable and enduring traditions in the residency was a dinner for the chief residents and their families in Dr and Mrs Sabiston's home on the evening before the formal chiefs' dinner, a private and personal conclusion to the residency.

Although his clinical practice spanned the spectrum of general surgery and cardiothoracic surgery, Dr Sabiston focused his research in cardiac surgery. He made significant contributions to the understanding of coronary artery blood flow, many of which led to innovative clinical therapies. He also conducted important studies on the diagnosis and management of pulmonary embolism and defined many of the mechanisms associated with thrombus formation and lysis and pulmonary injury. While funded from his first research grant from the National Institutes of Health, a Research Career Development Award, he became the principal investigator of a National Heart Institute grant that was funded continuously for 35 years. During his tenure at Duke University, he was also the principal investigator of a National Institutes of Health grant supporting an Academic Surgical Research Training Program, which supported the Duke Teaching Scholar in Academic Surgery program.

In addition to the large number of traditional scientific programs in general and cardiothoracic surgery that Dr Sabiston supported during his 30 years as the Chair at Duke, Dr Sabiston established the Surgical Oncology and Virology Program, recognizing the importance of research of retroviral diseases. From this Department of Surgery program, investigating the treatment of acquired immunodeficiency syndrome and other retroviral diseases, led by Drs Dani Bolognesi, Kent Weinhold, and Thomas Matthews, came 2 acquired immunodeficiency syndrome drugs - azidothymidine and the fusion inhibitor, T-20 (Fuzeon) - and a curative treatment of DiGeorge syndrome. ${ }^{1}$ That program has developed to include 10 funded investigators and a research budget of approximately $\$ 20$ million.

At one point in his career, Dr Sabiston was the editor of the Annals of Surgery, which he edited for 27 years, and the most prominent textbook in cardiothoracic surgery (Surgery of the Chest, which he co-edited through 5 editions, now in its 8th edition ${ }^{7}$ ), the most prominent textbook in general surgery (The Biological Basis of Modern Surgical Practice, which he edited through 14 editions, now in its 19th edition $^{6}$ ), and a textbook of surgery for medical students. Dr Sabiston published almost 300 peer-reviewed reports and more than 35 books on various facets of cardiothoracic and general surgery during his career. Dr Sabiston gave more than 200 lectures worldwide and was a visiting professor at more than 160 medical centers. He was also made an honorary member of 154 foreign surgical societies, including the Royal College of Surgeons of England, an honor that he shared with Dr Blalock.

The honors that Dr Sabiston valued most were the teaching awards from the medical students at Duke University, whom he held in the highest regard. ${ }^{4}$ Dr Sabiston's abilities as a teacher were highly appreciated by the medical students, with whom he met weekly when they rotated on the surgical service during the major clinical year. He was awarded the Golden Apple Award for excellence in teaching junior medical students on 4 separate occasions. Also, in 4 separate years, he received the Teacher of the Year Award, given by the graduating senior medical students to the most outstanding educator on the medical faculty. The ultimate teaching award was the Alpha Omega Alpha National Teacher of the Year.

Dr Sabiston was the president of numerous important surgical organizations, including the American Surgical Association, Society of University Surgeons, Southern Surgical Association, Society of Surgical Chairmen, and American College of Surgeons, one of the societies to which he was most devoted (Figure 1). He was the secretary of the Board of Governors in 1972 and served as the Chair from 1973 to 1975 , at which time he was elected to the Board of Regents and served as the Chair from 1982 to 1984. Finally, he was the president of the American College of Surgeons from 1985 to 1986. In addition, he was Chairman of the Surgery Study Section at the National Institutes of Health and the Chairman of the Research Committee of the American Heart Association. He was one of only few surgeons to be a member of the Institute of Medicine of the National Academy of Sciences.

Most notably, Dr Sabiston was the 65th president of The American Association for Thoracic Surgery (AATS), from 1984 to 1985 . Throughout his teaching with residents, he extolled the importance of the AATS, emphasizing its role in the promotion of scholarship and the development of academic cardiothoracic surgery. The AATS was the first meeting I attended, as a first-year resident, in Los Angeles in 1988, and I recall Dr Sabiston introducing me to Dr Paul Ebert, the 68th president. During the annual meeting of the AATS in 1985 in New Orleans, Dr Sabiston delivered his presidential address, "Observation on the Coronary Circulation." ${ }^{3}$ His address chronicled the events that contributed to the development of surgery for coronary 

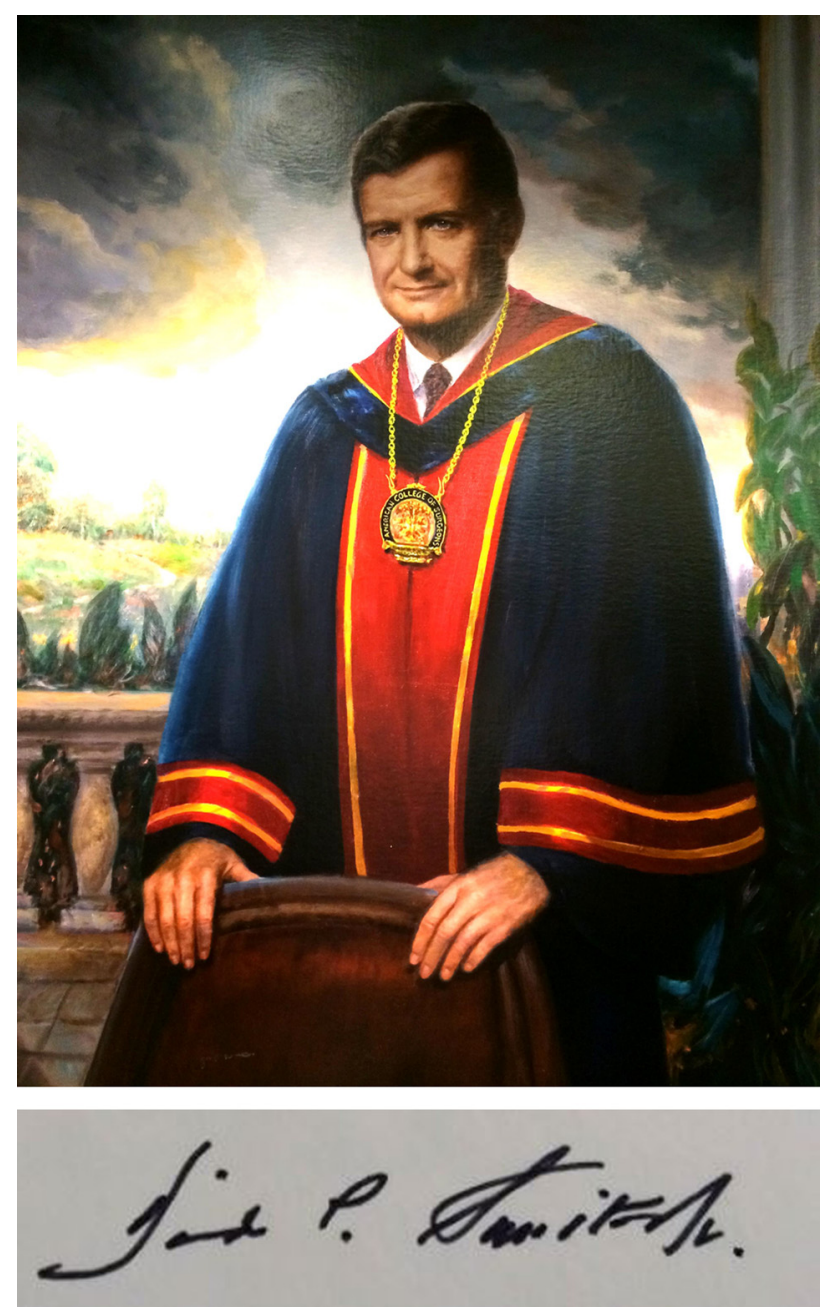

FIGURE 1. Top, Dr Sabiston as the president of The American College of Surgeons. Bottom, Dr Sabiston's signature.

ischemia, highlighting the roles of other academic cardiothoracic surgeons in the AATS.

It is impossible to cite his most important accomplishment or to measure the full extent of his influence; however, many believe that his career can best be summarized by his success in training academic surgeons. From 1964 to 1994, he trained 154 chief residents, of whom 95 became cardiothoracic surgeons and 59 became general surgeons (Figure 2). Of these, 103 achieved academic positions, and 41 became either division chiefs or department chairs. ${ }^{8}$ He was instrumental in the development of the careers of 4 subsequent presidents of the AATS: Dr Paul A. Ebert (68th), Dr James L. Cox (81st), Dr Fred A. Crawford, Jr (83rd), and Dr Thomas L. Spray (89th).

Those who enjoyed his mentorship will forever remember the most important tenets of his teaching, including "The patient always comes first," "Attention to detail," and "The master word in medicine is work" (from Osler). Another favorite was a quotation by Lord Kelvin, which

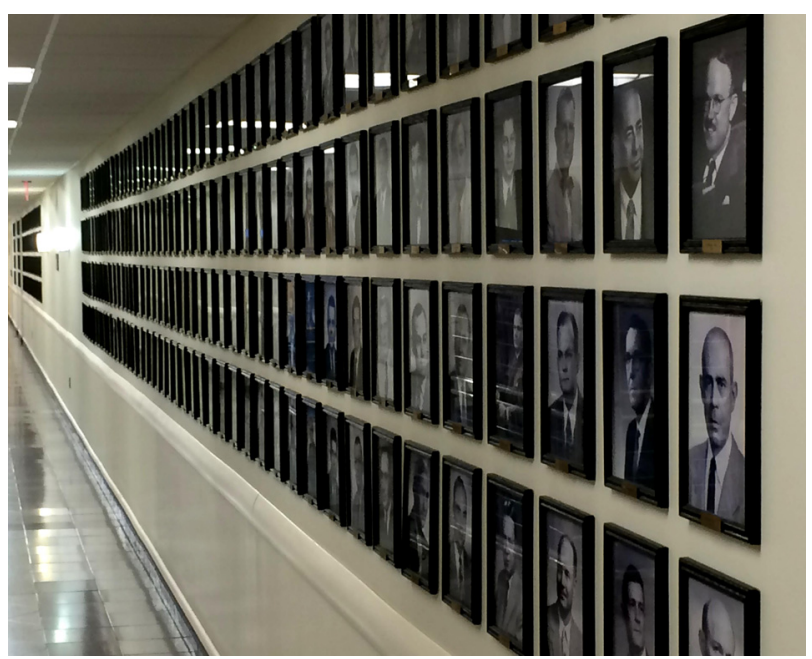

FIGURE 2. Photographs of all the surgical residents trained by Dr Sabiston currently displayed on the first floor of the surgery building at Duke.

he often abbreviated as "Numbers please!" but sometimes quoted (or asked a resident to research and recite) in its entirety ${ }^{9}$ :

I often say that when you can measure what you are speaking about, and express it in numbers, you know something about it; but when you cannot measure it, when you cannot express it in numbers, your knowledge is of a meager and unsatisfactory kind; it may be the beginning of knowledge, but you have scarcely in your thoughts advanced to the state of Science, whatever the matter may be.

A final quotation of note, which characterized the intensity of his mentorship and the importance of his commitment to cardiothoracic surgery, is a proverb that he attributed to David Lloyd George ${ }^{10}$ : "Don't be afraid to take a big step if one is indicated. You can't cross a chasm in two small jumps."

Dr Sabiston retired from surgical practice and from his position as Chair of the Department of Surgery in 1994. The final celebration of his graduating chief residents that year remains a bittersweet memory: his finale in the role of chair and program director coinciding with the completion of our training (his last chief resident class) that year. That graduation ceremony included his last formal address to the Department, during which he again highlighted the virtues of scholarship and academic thoracic surgery and his hope for the future.

He became Director of International Programs at Duke University Medical Center, and he continued to involve himself in the academic progress of the Department of Surgery, without compromising his successor, Dr Robert W. Anderson (Figure 3). During the years after his retirement, he frequently came to his office, despite failing health, attending academic functions and meeting with residents 


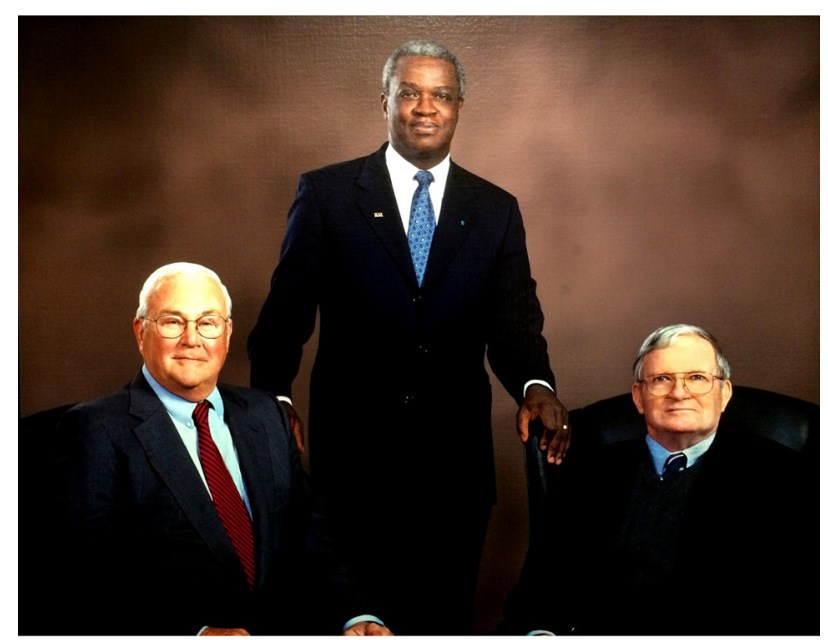

FIGURE 3. Right, Dr Sabiston with his the first two David C. Sabiston, Jr, Professors of Surgery, left, Dr Robert Anderson, Chair from 1996 to 2004, and, center, Dr Danny Jacobs, Chair from 2004 to 2013.

and junior faculty to continue to stimulate ambition and to mentor academic careers (including nominating me as a member of the AATS). He died of chronic complications of a cerebrovascular accident on January 26, 2009.

Many have attempted to summarize his career, but the magnitude of his contribution to academic surgery can never be characterized. One of his closest friends, Dr Rollins Hanlon, eulogized him eloquently ${ }^{11}$ :

In January 2009, the surgical world lost a great light when David Coston Sabiston, Jr, peacefully expired at the age of 84 after a long illness. Having recovered significantly from a severe stroke in 1997, he was struck down again 4 years later in an episode that brought to a public end one of the most distinguished careers in modern surgical history. He was a man in full, who aimed to emulate his professor, Alfred Blalock; in this effort, he succeeded and indeed surpassed his mentor in the number of academic disciples from his own program. Formed in an uncompromising tradition, these surgeons represent a superlative legacy of this teaching colossus.

Dr Hanlon was correct: the light did not entirely extinguish. The torch is carried by those he touched, the medical students, residents, faculty, visitors, and colleagues who were witness to what academic surgery could be at its best. It was not easy to achieve: it involved intense personal commitment, sacrifice, and vision. What is left then, for those who experienced his mentorship, is to pass that torch to the next generation, although we may never match his aptitude or his effort. ${ }^{12}$ Perhaps the best way to summarize his career is to recognize Dr Sabiston's own comments regarding his mentor Dr Blalock, quoting Henry Brooks Adams: "A teacher affects eternity, he can never tell where his influence stops." 1

\section{References}

1. Haynes BF. At the Heart of Medicine: Essays on the Practice of Surgery and Surgical Education. Durham, NC: Carolina Academic Press; 2005.

2. Biography of David Coston Sabiston, Jr. Durham, NC: Duke Medical Center Archives; Available at: http://medspace.mc.duke.edu/sabiston/biography.html. Accessed June 30, 2014

3. Sabiston DC Jr. Observations on the coronary circulation: with tributes to my teachers. J Thorac Cardiovasc Surg. 1985;90:321-40.

4. Wells SA Jr. David Coston Sabiston, Jr.: surgeon, scientist, teacher, and leader. Clin Cardiol. 2002;25:43-5.

5. Sabiston DC. Alfred Blalock [Presidential Address at the American Surgical Association]. Ann Surg. 1978;188:255-70.

6. Townsend C, Beauchamp DR, Evers MB, Mattox KL, eds. Sabiston's Textbook of Surgery: The Biological Basis of Modern Surgical Practice. 19th ed. Philadelphia: WB Saunders; 2012.

7. Selke FW, del Nido PJ, Swanson SJ, eds. Sabiston and Spencer Surgery of the Chest. 8th ed. Philadelphia: Elsevier Science; 2010.

8. Chitwood WR. The Sabiston heritage: excellence in surgical education. Ann Surg. 2003;238(Suppl):S3-17.

9. William Thompson 1893. Available at: http://www.atmos.washington.edu/ $\sim$ robwood/teaching/451/Lord_Kelvin_quote.pdf. From PLA, vol 1, "Electrical Units of Measurement," 1883-05-03. Accessed June 30, 2014.

10. Schuman FL, Brodsky GD. Design for Power: The Struggle for the World. New York: Alfred A. Knopf; 1941.

11. Hanlon CR. In memoriam: David Coston Sabiston, Jr., MD, FACS. Available at: http://www.facs.org/fellows_info/bulletin/2009/2009-may-bulletin. pdf\#page $=38$. Accessed June 30, 2014.

12. Pappas TN. A debt unpaid, remembering David Coston Sabiston. Ann Surg. 2009;249:706-7. 